\title{
دراسة تحليلية عن مدى الملاءمة بين خريجي المدرسة وفرصة العمل
}

\author{
أسيب أحمد فتح الرحمن \\ محاضر التفسير التربوي وعلم التربية في الجامعة الإسلامية "نوسانترا" ش. سوكارنوا حتى باندونج جاوى الغربية \\ Email: a_fathurrohman@yahoo.com
}

\begin{abstract}
ملخص البحث
كانت الملاءمة بين الخريجين وفرصة العمل من الأمور المهمة لدى المتعلمين ووالديهم. وهي إحدى إلى المؤشرات من بحاح برنامج التعليم. والغرض من هذه الدراسة هو تحديد إستعداد الحكومة لتنفيذ المناهج الدراسية با ب ץ، مع العلم بإستراتيجية لبناء الصلة بين التعليم والعمل، ومعرفة عقلية الطلاب لريادة الأعمال، ومعرفة التعلم المتكامل الذي يدمج أنواعا مختلفة من التعليم. استخدم هذا البحث الطريقة

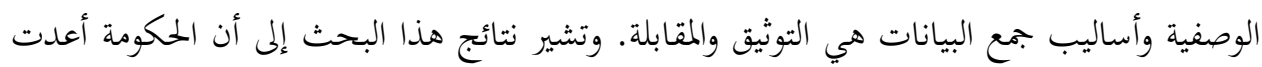
المناهج r ا • r تدريجيا. لقد قررت الحكومة إلتزام التعليم و سنوات بل في عدة مدن يتطلب التزام

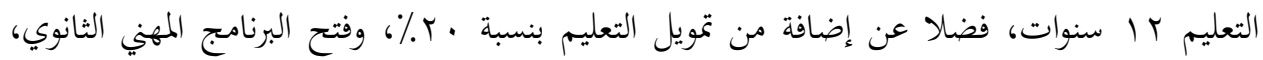
بإطار الفكر أن خريجي المدرسة قادرون على خلق فرصة العمل. إن بناح تلك الملائمة يجب أن تدمج بحموعة واسعة من التعليم من خلال التمكين والتواصل مع جميع أصحاب المصلحة. المصطلحات الرئيسية: الملاعمة، خريجو المدرسة، العمل
\end{abstract}

\begin{abstract}
The Relevance of student graduates with the job they achieved are very important. This condition meets both the the hopes and ambitions of students and parents. It goes without saying that this is one indicator of the success of education program. The study was aimed at determining the preparation of the government to implement the curriculum in 2013, investigating the strategy to build the relevance between education and work, scrutinizing students' mindset concerning the relevance of education and work. This study used descriptive analysis which is qualitative approach in nature. The findings of this study show that the government has prepared the curriculum gradually in 2013, and the government has administered 9 years school program, some district-State has already applied the 12 years education program, as well as it has spent education funding by $20 \%$, and it has opened the program Vocational High School (SMK). Students' mindset graduated from SMK has shifted from job-seeking to job-creating because they have sufficient
\end{abstract}


أسيب أحمد فتح الرحم

skill. The degree of relevance between what students learn and what the society need is dependent upon collaboration among all stakeholders.

Keywords: Islamic Education, Graduates and Job

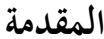

إن تقدّم الزمن يمرّ سـريعا طبعا بتحدياته وتوقعاته مباشـرا كانت أو غير مباشـر. أمـا الناحيـة

المباشرة مثل التعامل مـع الأجنبيين أو العجـم للحاجـة التعليم أو العمل أو المفاوضـة أو متبادلة الفكرة

وغيرها. وهذه الممكنات نتيجة من سهولة الإتصالات والنقل من قرية إلى قرية بل من بلد إلى بلد وبين قارة إلى قارة بركوبة الحافلات أو القطار أو الباخرة أو الطائرة. لذلك هناك سكان سيكان يسكنون في المدينة

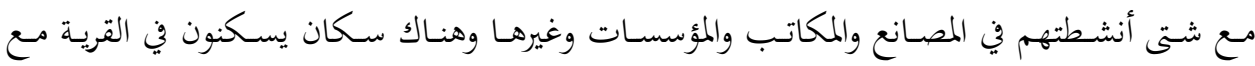
أنشطتهم في المزرعة والريف وصيد السمك وغيرها.

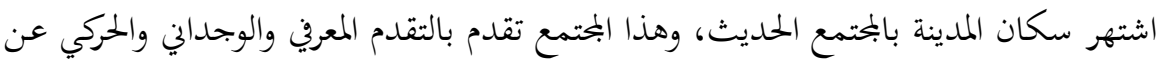
طريق التعلم إمـا شريعة أو تقليدية. لـذلك قال محمد شـيد (دون السنة، ص. ب ا) "لا يتم تطهير المجتمعات بالتشريع والعقوبة وحدهما، ويمكن الموازنة بين بحتمع حديث كمجتمع أمريكا وبين بجتمع

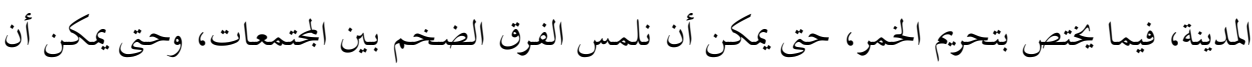
نتصور القيمة العالية التى وصل إليها بحتمع المدينة بتربية القرآن".

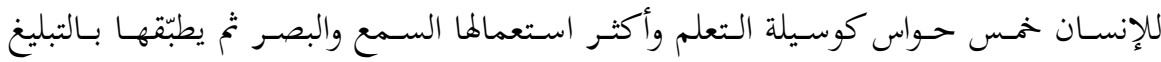
والكتابة. وحـثّ عليهما القرآن منذ أربعة عشر قرنا. وكلمة (إقرأ...) فيه تكون أساسا ومبدأ لمفتاح العلوم والثقافة والحضـارة والتي هي سر تقـدم الأمـم وتفوقها، بـل رب مسـم ومسـمة تلاهـا وتلفظها بلسان فصيح وصوت بليغ وقلبه مطمئن بتلاوته والحكمة فيه والفوائد البليغة، لذلك تلاوته تلاوة ظاهرة ليست باطنة. قال رسول الله: ( يخرج ناس من قبل المشرق ويقرؤون القرآن لا يجاوز تراقيهم يمرقون من ون الدين كما يمرق السهم مـن الرمية ثم لا يعودون فيه حتى يعود السهم إلى فوقه ). قيل مـا سيماهم ؟

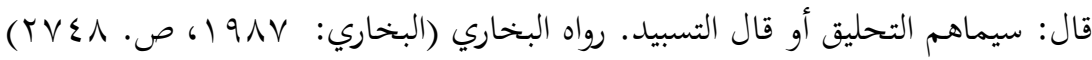
دل هذا الحديث على ذم من قرأ القرآن ورلكن عمله وأخلاقه بخلاف ما تلاه من القرآن الكريم على الرغم ليس معناه تقلّل بحرد القارئ لأن القرآن هو المتعبّد بتلاوته فهل من مزيد تلك القراءة أفضل وأحلى حهلاوة التلاوة لأن الإيمان يتمثل مـن قول وتصديق وعمل. و وإذا ذهبـت تلك العناصر فيكون فاسقا كمؤمن عاص أم منافقا لتعارض القول والتصديق، يؤكد ذلك على وقاية القول والتصديق والعمل 
معا بتقوية العوامل الداخلية والخارجية والهداية من نور الله. نسمع كثيرا من المسلمين عندما يصلون وهم يقولون "اللهم يا مقلب القلوب ثبت قلبي على دينك وطاعتك واستقامتك" سمي القلب لسرعة تقلبه. أمـا تقوية العوامل الداخلية تكون بإملاء المخخ والعقل والقلب بـالعلوم والفكر والذكر وتغليبب النفس على العمل الصالح يرفعه، ومن ذلك دوام الصلوات الخمس جماعة خحالصة لله. وتناول العلوم

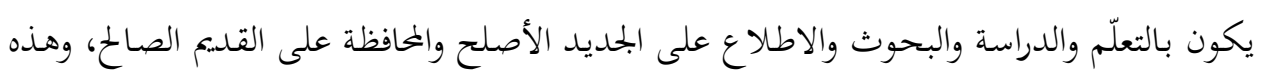
من موقف العالم العارف بالله تعالى.

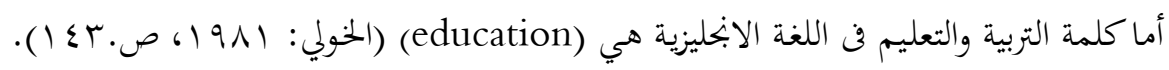
صار هذا المصطلح مـن الأهمية لأن كثيرا مـن المتخصصسين يرجعون إلى مصادر التربية والتعليم المتعلقة بالمصطلحات الحديثة. ونشأ هذا التعلّم مـن الخطوة الأولى وهي القراءة التي تزيد المعرفة والاستطاعة

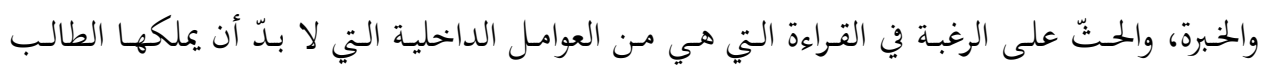
والدارس والباحث، ولا يكفى هذا الحثث بحرد رغبة القراءة، بل لا بد أن يطبقه الطالب مرتحلا في حياته اليومية بدون التخطيط والأمر حتى تكون عادة للمرء. ونشأت هذه الرغبة لأشياء بحتذبة القلب والنفس حتى ساق القلب والنفس مريحة وسكينة، فوسائل الترويح هي الفهم إلى الهدف والغاية من الإدراك، كم من طالب رغب عن طلب العلم لعدم العلم بالهدف والغاية من طلبه فاجتنب منه وبقي حياته من الكسالى بدون إبداع وابتكار والتالي كان من الجمود والتخلف، وهذا الواقع يدل على أن التقدم نتيجة من العلوم المستخدمة.

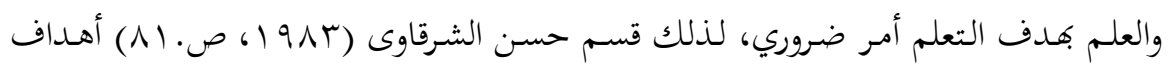

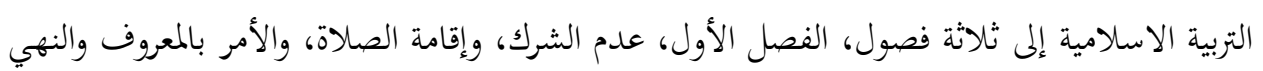

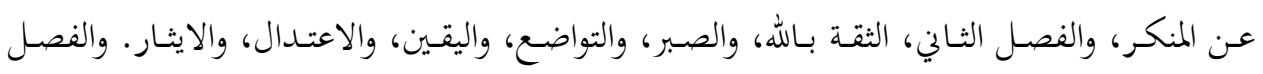
الثالث، الإحسان، والوفاء، والزهد، والطاعة والقنوت.

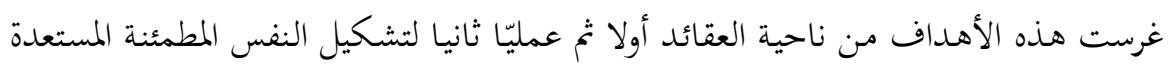
لمواجهة الحياة الشـيدة بكل أنواع الغرور والمكيدة التي تصعد النـاس أثناء طريقه اليومية إمـا في بيئة

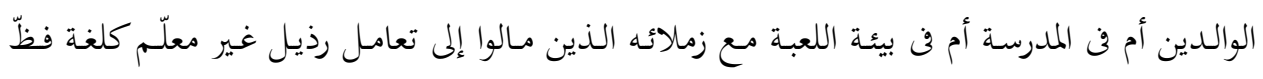

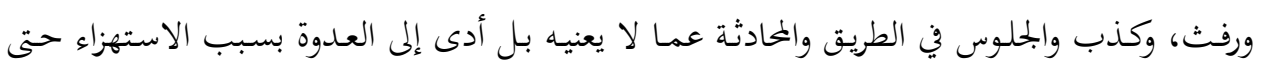
يوشك إلى التنازع بالضرب واحدا فواحدا ثم نشر بين فرقة وفرقة بسبب استفزاز وأهمية أخرى دينا كان أم سياسيا كان أم إقتصاديا كان أم حزبا وغيرها. 
أسيب أحمد فتح الرحم

وأهداف التربية ليست بحرد المد المعرفي بل أوسع من ذلك وهي المد الوجداني والحركى. وزعم الناس أن أهداف التربية هي لنيل العمل بسهولة مثل أن يكون عاملا أو موظف الحكومة بأجرة ثابتة

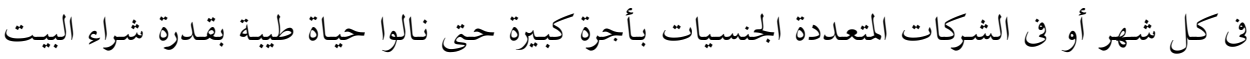

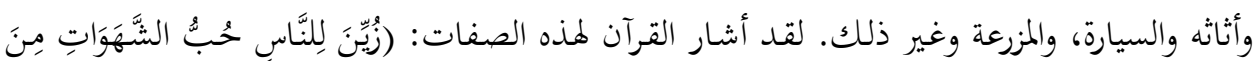

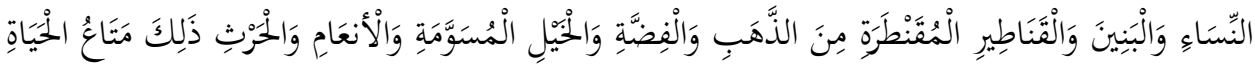

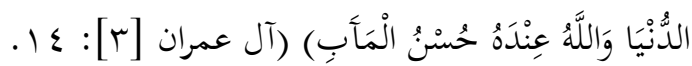

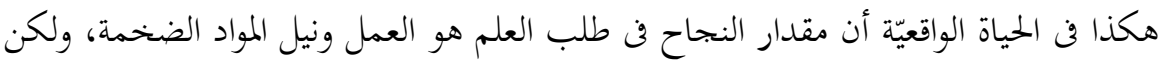

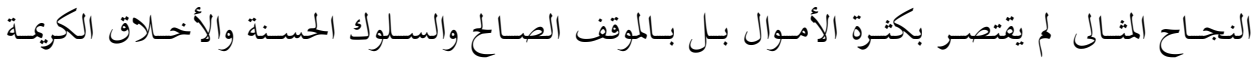

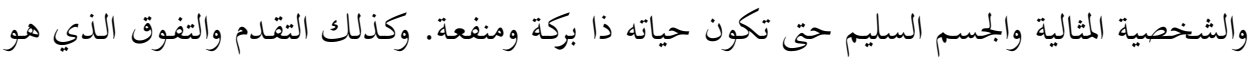

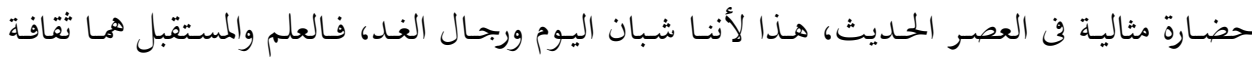
وحضارة يلزم لنا مواجهة أيّ تحديات العصر وتحقيق التوقعات. قال سعيد إسماعيل (1990، ص.11) إن للشخصية ثلاث مستويات: المستوى الاول هو

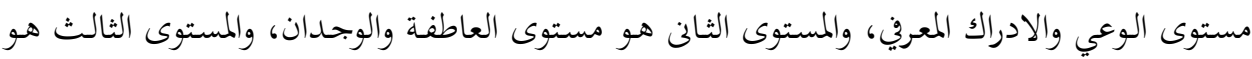
مستوى الحركة والنزوع والمهارة.

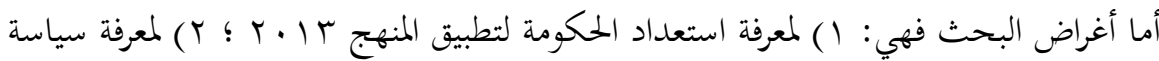

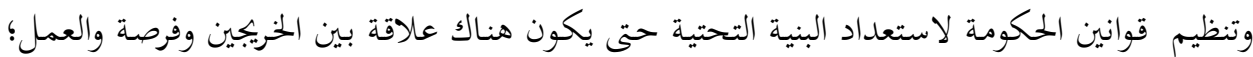

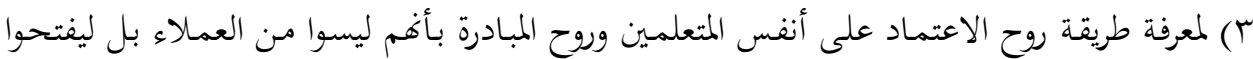

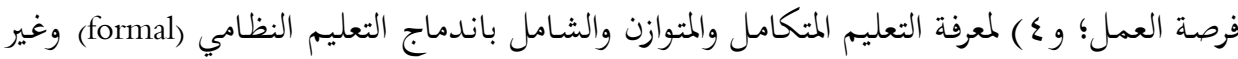
النظامي داخل بيئة البيت وخارجه (informal, non formal).

أما الطريقة التي استخدمها الباحث هي الطريقة الوصفية وأساليب جمع البيانات هي التوثيق

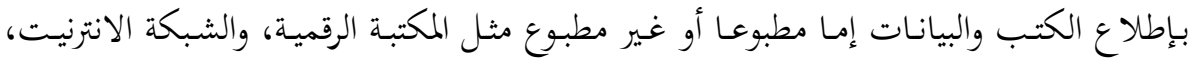
والمحلات والجرائد والمقابلة.

البحث استعداد الحكومة لتطبيق منهج ب ا ب ب في المدارس كان أمر التربية والتعليم من وظيفة الحكومة الذي لابد عليهم أن تؤديه كما ورد في القانون

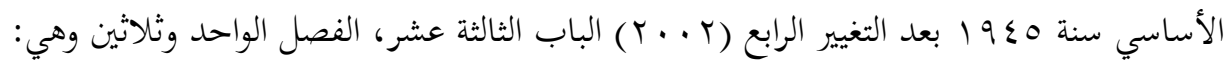




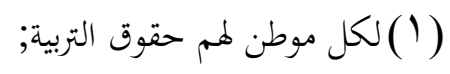

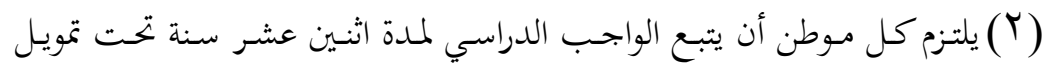

$$
\text { الحكومة؛ }
$$

(ب) اتحه نظام التربية الوطنية لترقية الإيمان والتقوي لنيل الأخلاق الكريمة في تزكية

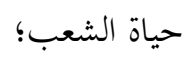

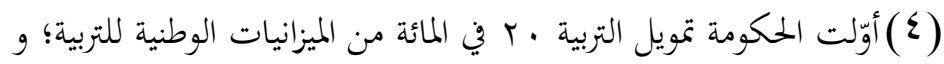

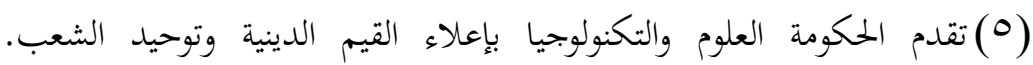

فسرت الحكومة من هذا القانون الأساسي بإنشاء القانون عن نظام التربية الوطنية رقم · r سنة

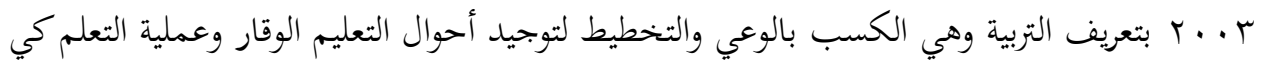

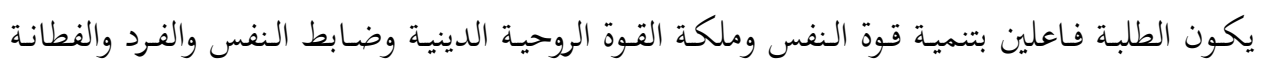

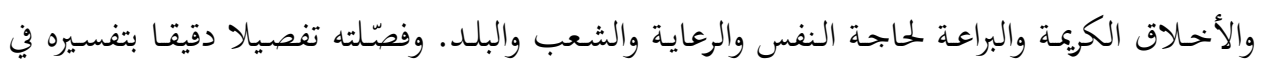

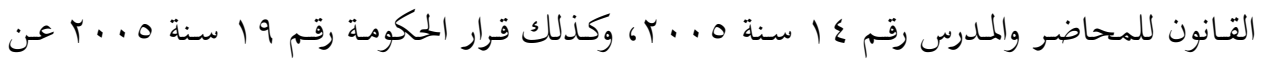

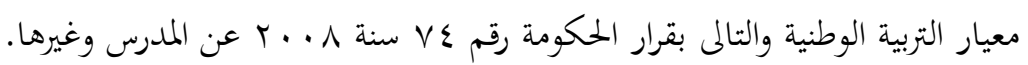

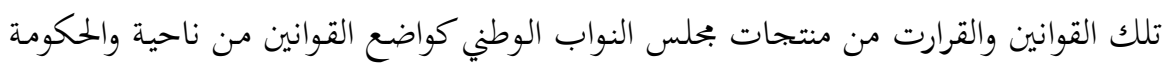

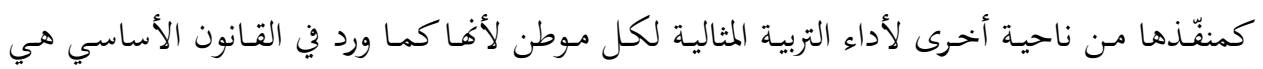
حقوق الموطنين.

للتربية عناصر أساسية منها الهدف والمدرس والمتعلم والمنهج والطريقة والتسهيلات. وكلها تحت

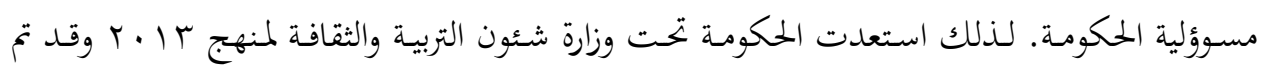
تنفيذه بعض المدارس، أعلنت الحكومة بأن تنفيذه سيكون تدريجيا أولا من المدارس الحكومية (العامة)

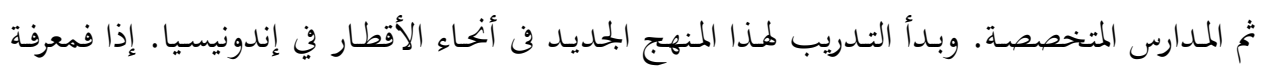
الفرق بين المناهج السابقة والحالية أمر مهم في هذا البحث كما ورد في هذا الجددول التالى:

\begin{tabular}{|c|c|c|c|}
\hline 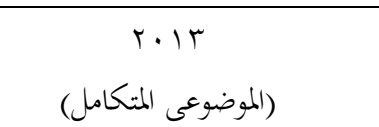 & $\begin{array}{c}\text { KTSP } \\
r \ldots r\end{array}$ & $\begin{array}{l}\text { KBK } \\
r \ldots \varepsilon\end{array}$ & 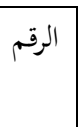 \\
\hline معايير الكفـاءة معتمـدة على & \multicolumn{2}{|c|}{ معايير الكفاءة معتمدة على معايير الختوى } & .1 \\
\hline
\end{tabular}

\section{الجدول}

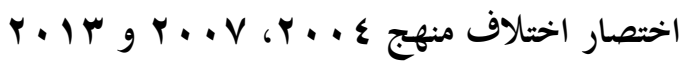


أسيب أحمد فتح الرحم

\begin{tabular}{|c|c|c|c|}
\hline احتياجات البختمع & & & \\
\hline معايير المحتوى مستمدة من معايير & \multicolumn{2}{|c|}{ معايير المحتوى مستمدة من معايير كفاءة الموضوعات } & r \\
\hline فينغي لمجميع المواد الدراسية المساهمة & \multicolumn{2}{|c|}{ المكونة بين موضوع تشكيل المواقف وتكوين المهارات والمعارف } & r \\
\hline الموضوعات مستمدة من الكفاءة & \multicolumn{2}{|c|}{ الكفاءات مستمدة من الموضوعات } &.$\varepsilon$ \\
\hline $\begin{array}{l}\text { لا بد أن تكون جميع المواد الدراسية من الكفاءات الأساسية (لكل فصل) }\end{array}$ & \multicolumn{2}{|c|}{ الموضوعات ينفصل بعضها عن بعض } & .0 \\
\hline 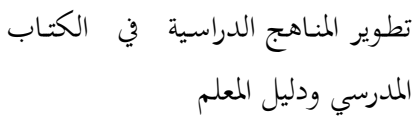 & للكفوير المنـاهج الدراسـية & لمقوير المنـاهج الدراسية & .7 \\
\hline 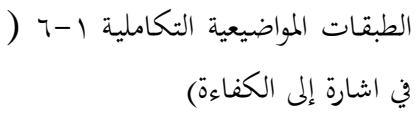 & 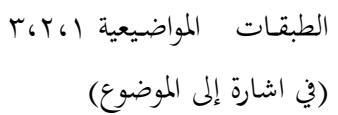 & 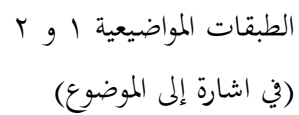 &. $\mathrm{V}$ \\
\hline
\end{tabular}

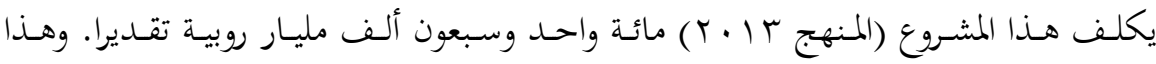
التكليف أكبر تكليف من تاريخ تغيرات المناهج منذ الاستقلال. وهناك رفضاء لهذه المنهج الذي أدي إلي وظيفة زائدة للمدرسين، بل المشكلة تكون في المصطلحات والشكل الجحديد للوجه المطلوب للمنهج بتغير المواد والكتب الدراسية، مع أن كثيرا من المدرسين لا يفهمون فهما جيدا للمنهج قبله يعني منهج KTSP يجري فعاليا. على رغم ذلك كانت حاجة لتغيير المناهج الدراسية هي ضرورة، لأنه طريقة لإجابة تحديات الزمان، وهذه التحديات هي حاجة الناس المادية والجسمية والنفسية والروحية. وتحقيق لمذه الحاجة هي لهي التغيير، يحب أم يكره، وينبغي ما زال على استعداد لقبول ولتنفيذ هذا المنهج الجحديد. وتنفيذ هذا المنهج يمتاج إلى وقت طويل وصبر وفير وجهد كبير لتحصيل المحصول ونيل النتيجة اللامعة.

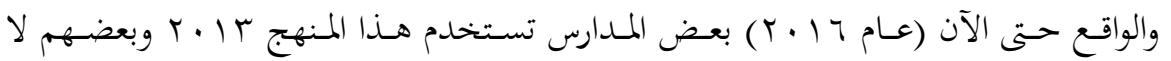
تستخدمه، ويكون هـا بسبب مختلف الأحسوال والأمـاكن البعيدة والإيرادات المحلية والموارد البشرية. ونشأت هذه الفجوة بسبب تطبيق الحكم الذاتي الإقليمي لقسم التربية، ومـ تم فعميد المدينة تقضي وتقرر لبرنامج التربية مع تمويله طبعا بموافقة بحلس النواب الاقليمي (DPRD). وهذه النواحي تدل

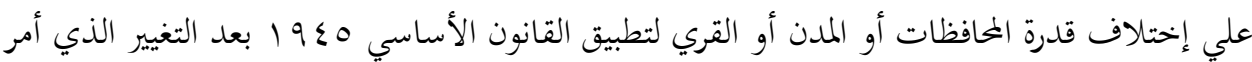


الحكومة لأداء تمويل التعليم · ب في المئة غير أجرة الموظفين من المعلّمين. لذلك فمساهمة مركز الحكومة

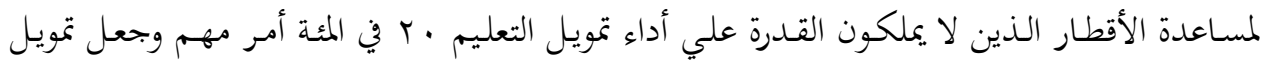

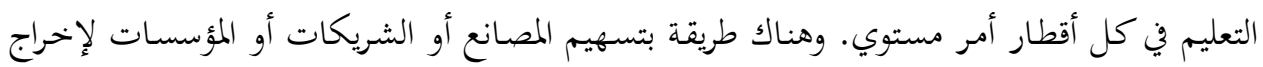
المساعدة الواجبة ويسمي بأخرى (CSR) أو شركت مع بيت المال والتمويل.

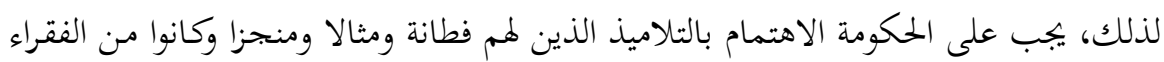

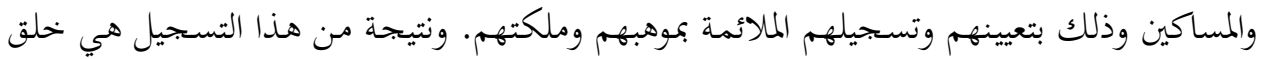

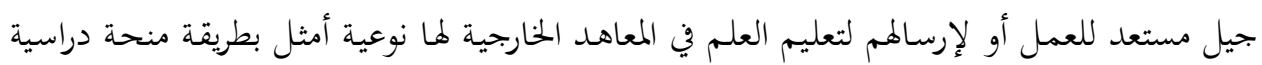
إما من الحكومة أو من المساعدة الخارجية أو من تمويل المصانع والشريكات والمؤسسات وغيرها. وهذا لإنسا

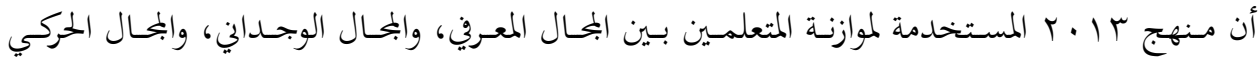

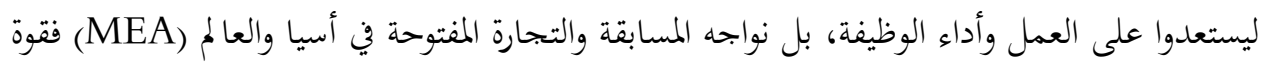

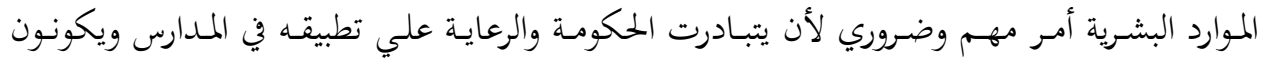
خريبين مستعدين لمواجهة المسابقة بين البلدان بل بين القارة.

سياسة وتنظيم قوانين الحكومة لاستعداد البرامج الدراسية حتى يكون هناك علاقة بين الخريجين

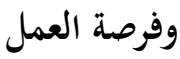

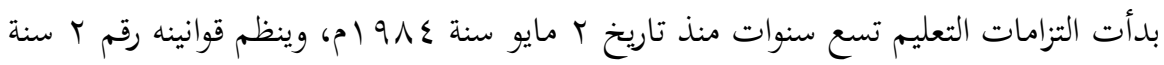

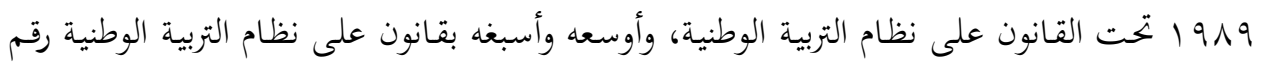

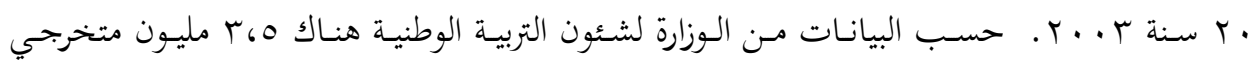

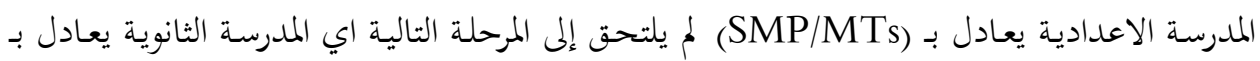

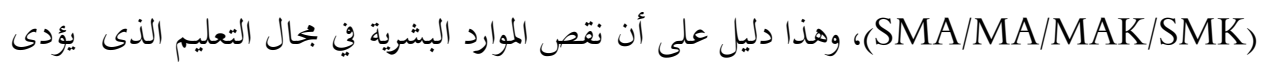
إلى نوعية رديئة ونقص التنافس فن نيل الوظائف وطنيا كان أو دوليا.

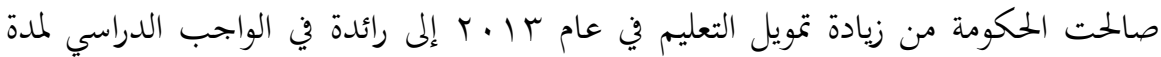

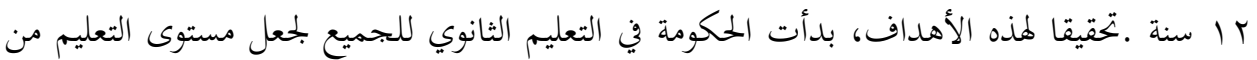
المدرسة الثانوية (SMA/MA/MAK/SMK) تصبح أكثر يسرا. ويبقى التعليم الأولوي مخصصات

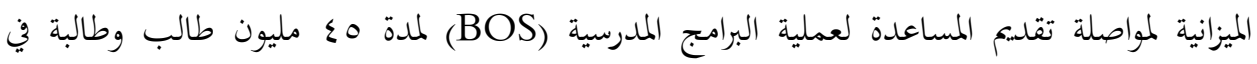

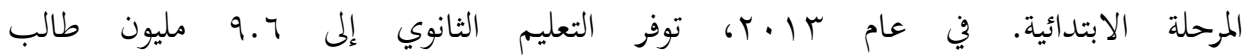
.(SMA/MA/MAK/SMK) 
أسيب أحمد فتح الرحم

كما قررت الحكومة الواجب الدراسي لمدة و سنوات بل في عدة مدن يتطلب بتنفيذ الواجب

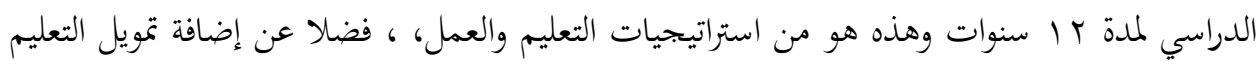

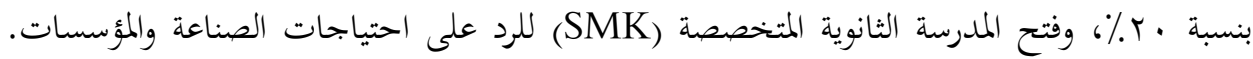
وهذه العوامل لها صلة لتوزين خريجي المدرسة والعمل حتي تكون ملائما بينهما.

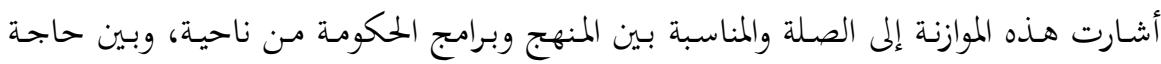
فرصة العمل (حاجة الناس) يوميا ومستقبله من ناحية أخرى كما في الجدول الآتى: r. الجددول ris

الصلة بين المنهج وحاجة فرصة العمل

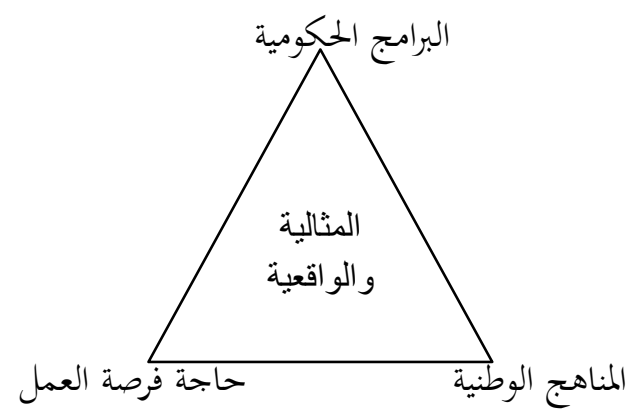

تكاملت هذه الصلة إذا كانت هناك مناسبة بين النظري والتطبيقي للقوانين وعمليته في الميدان

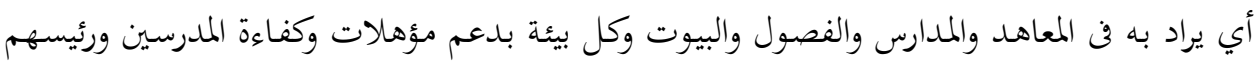
وكذلك بالمواد والموارد الاكاديمية.

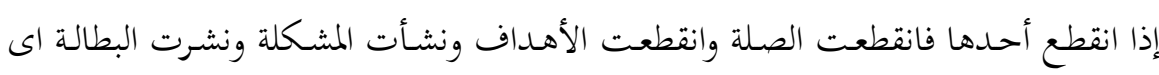

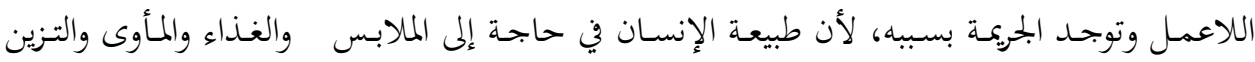

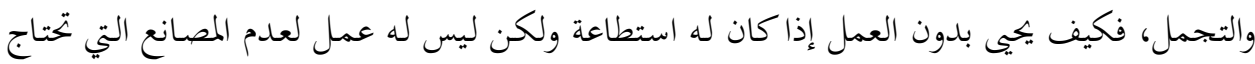
إليه.

لمواجهة هذه القضايا والمشكلات فيجب أن يكون على كل طالب الروح والقوة العقلية، كما

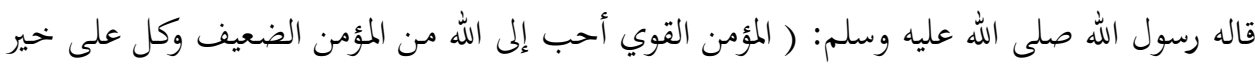

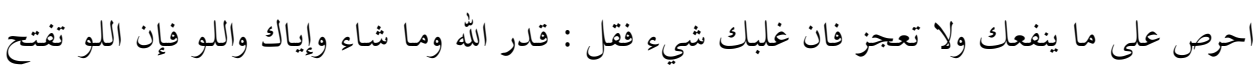

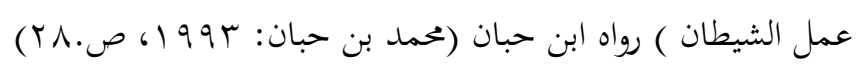


هذه القوة تشتمل على قوة الجسم والعقل والروح والمال والمعارف والوجدان والحركى وغيرها من

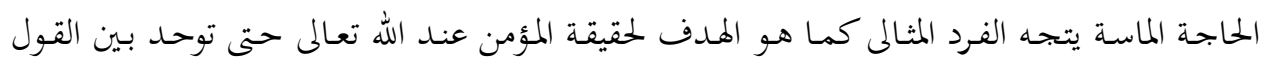

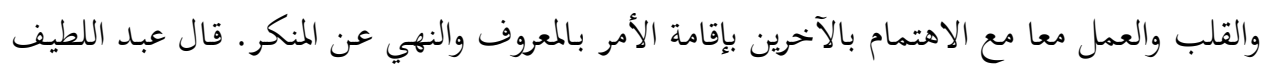

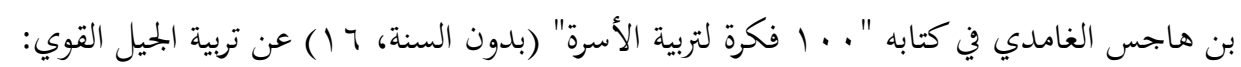

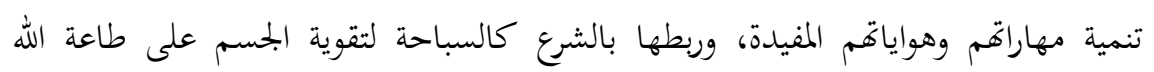

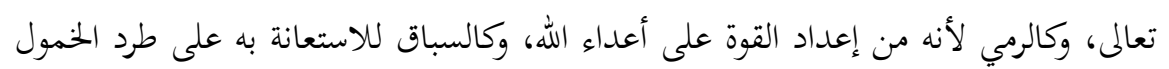

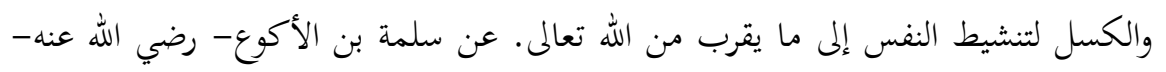

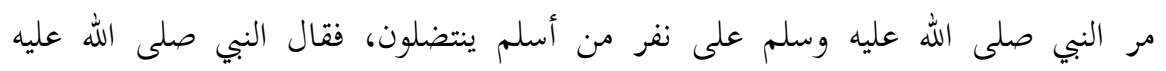

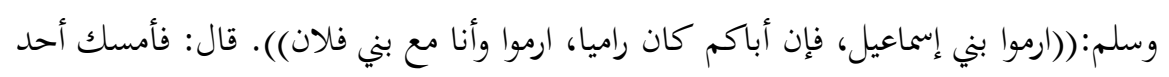

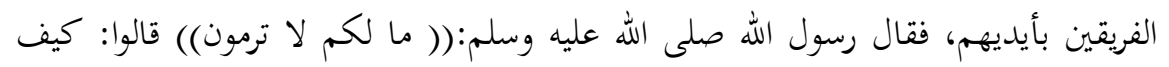
نرمي وأنت معهم؟ قال النبي صلى الله عليه وسلم: (ارموا فأنا معكم كلكم).

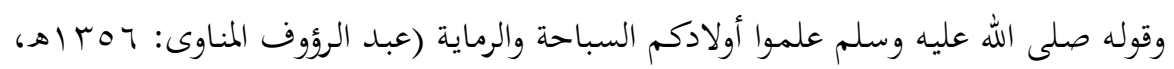

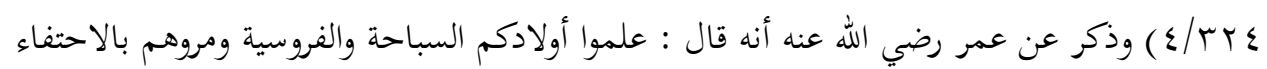

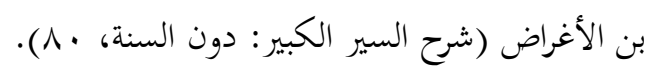

وتدعم هذه القوة الناجحة بالمنهج المناسب لكل فرد لأن الفروق الفردية من سنة الله تعالى ولها

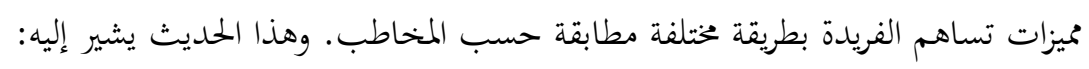

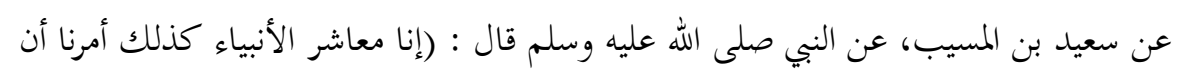

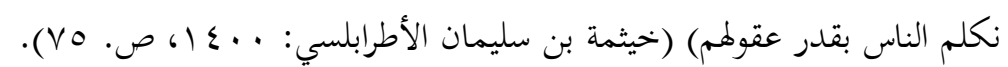

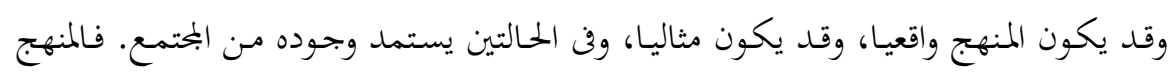

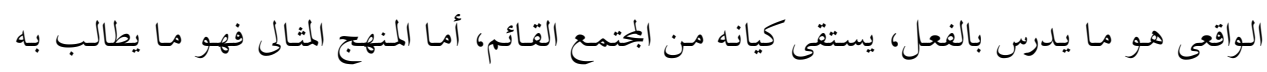

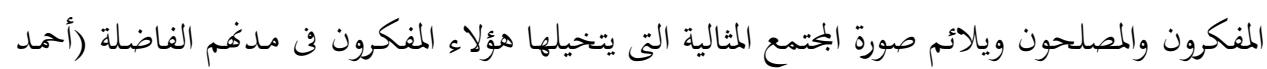
فؤاد الأهوانى: دون السنة، ص. • 17 (1).

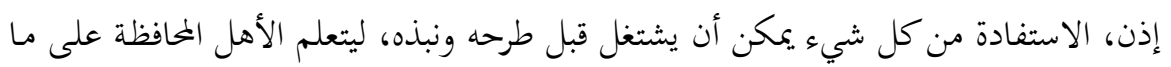

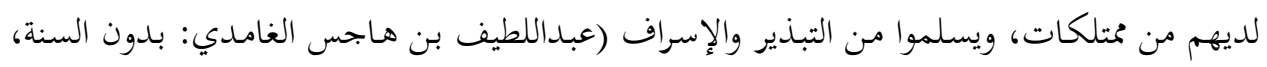

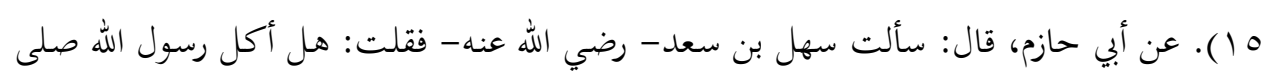

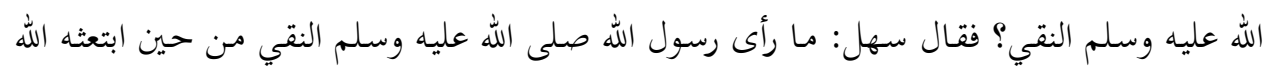


أسيب أحمد فتح الرحم

حتى قبضه. قال: فقلت: هل كانت لكم في عهد رسول الله صلى الله عليه وسلم مناخل؟ قال: ما رأى : مالى

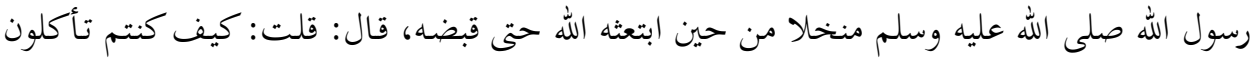

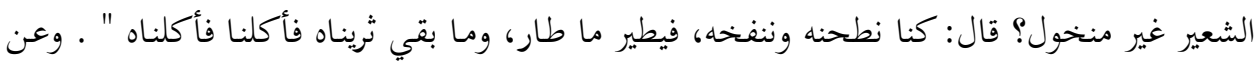

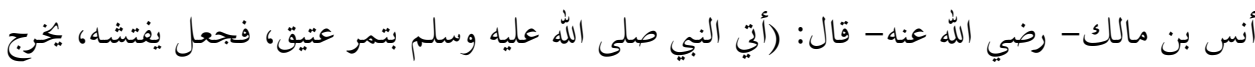

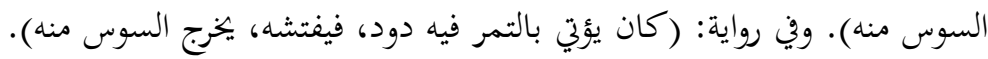

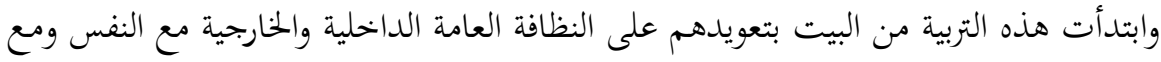

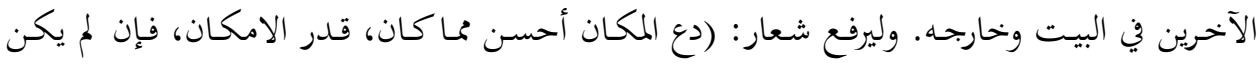

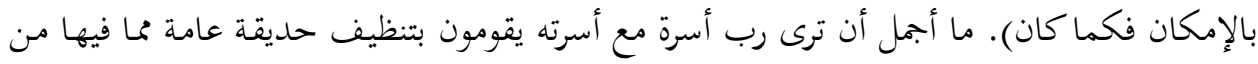

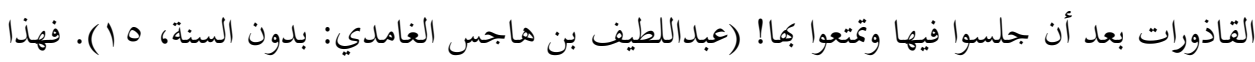

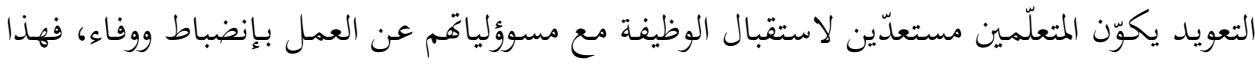

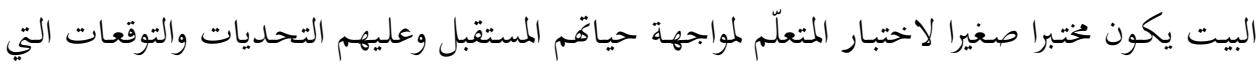
تختلف بعصور من العصور. إذا من هذا المنطلق، فالطريقة أهم من المادة، ولكن كان المدرس أهم من الطريقة، وروح المدرس فئس

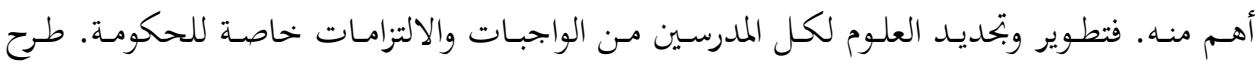

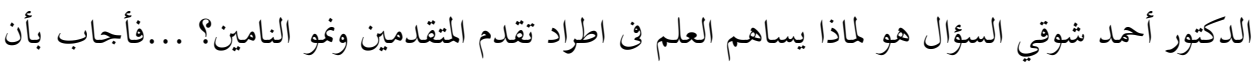

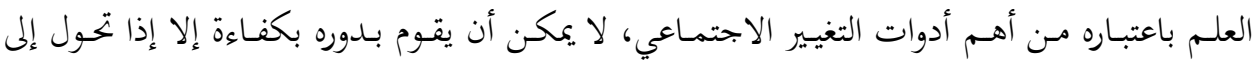

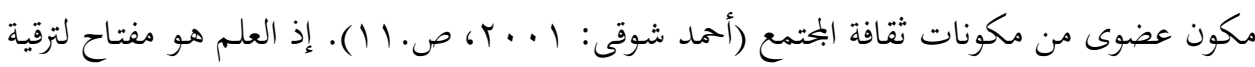

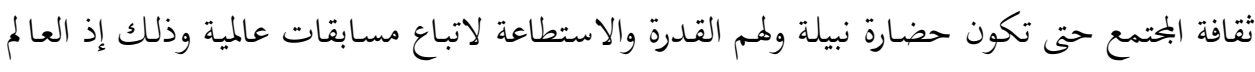
كقرية صغيرة بتقدم التكنولوجيا وجاء العصر الرقمي إزاء العولمة والثورة الثالثة.

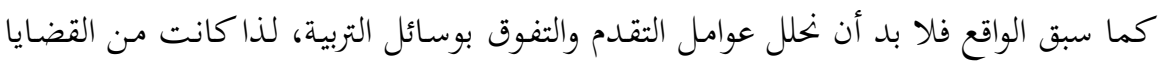

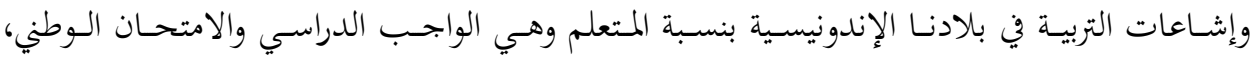
واشتباكات الطلاب، وحرية التعامل، وغيرها.

أما بنسبة المعلم وهي شهادة المعلم، ومؤهلات المعلمين وكفاءقم. وأما بنسبة إقتصادية التعليم

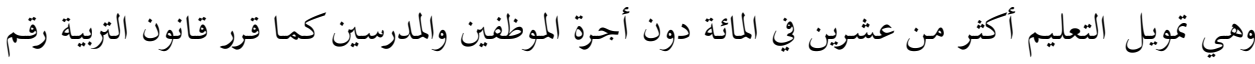

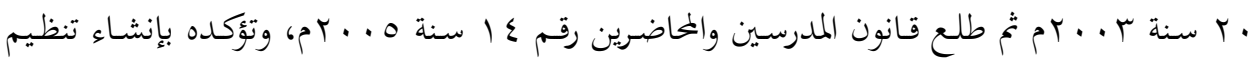

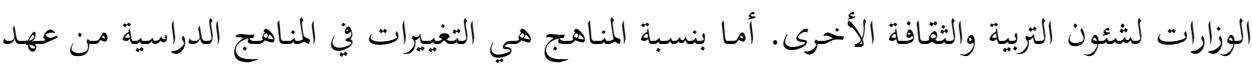




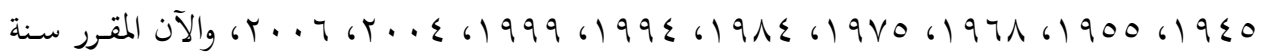

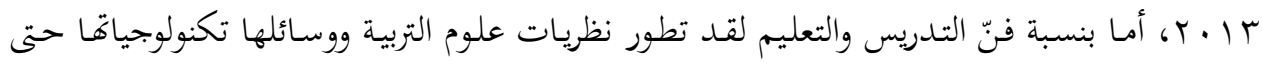
ينشأ تعليم مع بعد (distance learning) بوسيلة الشبكة الدولية والقرص وفلاش المؤكدة بالحاسوب المستخدمة التى هي التكنولوجيا العالية. وكذلك تطورت المواد التعليمية، أها لا تقتصر بالكتب المطبوعة فسحب بل بالمكاتب الحاسوبية منها: المكتبة الاكترونية (Electronic Library)

المكتبة المهججنة (Hybrid Library)

المكتبة الافتراضية (Virtual Library)

المكتبة المستقبل (Library of Future)

المكتبة الرقمية (Digital Library)

With Out Wall،(Lib) المكتبة بدون جدرأن المديه (1)

البوابات (Portal, Cyber Library)

ويمكن القول بأن هذا العصر ينتقل إلى المرحلة الحالية (أو الثورة الثالثة) والتي هي نتاج للعصر

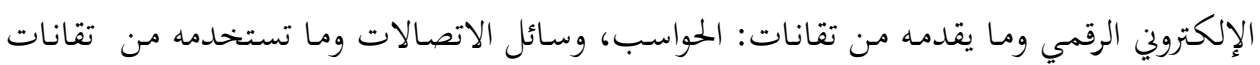

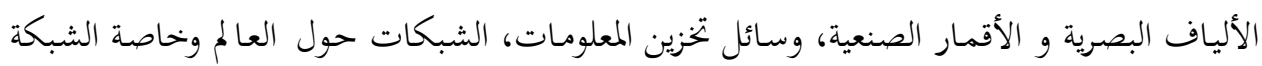
العنكبوتية (الإنترنت)، الكاميرات الفيديوية الرقمية وغيرها من الوسائل. والحق أن عالم اليوم الذى نسكن فيه هو عالم مليء بالمعلومات (الصور والصوت) عبر الوسائل

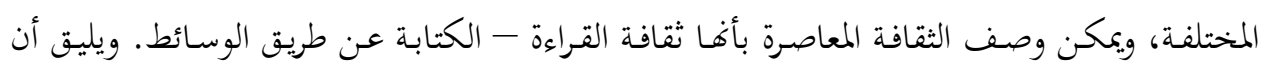
نطرح السؤال الناقد هو: هل يمكن لأطفال وشباب اليوم أن يكونوا فاعلين في عالم المستقبل إذا تلقوا علم البارحة؟ وهل بوسع الأساتذة أن يتجاهلوا الأدوات المتوفرة التي يستعملها المهنيون الآخرون؟.

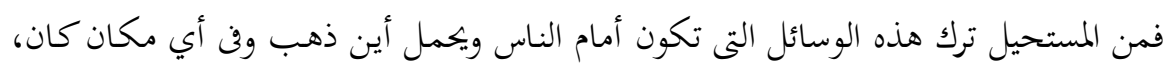

$$
\begin{aligned}
& \text { صار هذا من واجبات والتزامات مع المعرفة بفوائد استخدام المكاتب الرقمية منها: } \\
& \text { تطبيق مبدأ الفعالية والكفاءة } \\
& \text { تسهيل لتجميع المعلومات والمراجع الخاصة والعامة }
\end{aligned}
$$

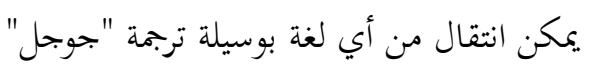

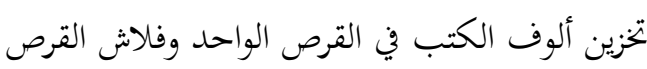


أسيب أحمد فتح الرحم

دوام الحاجة إلى التعليم والتدريب وذلك بسبب التطور في مختلف بحالات العلوم.

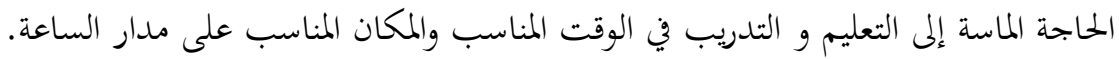

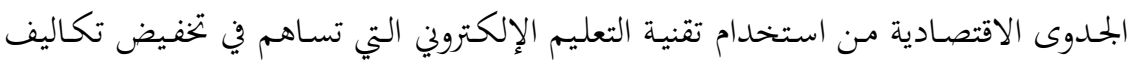

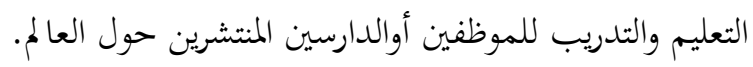

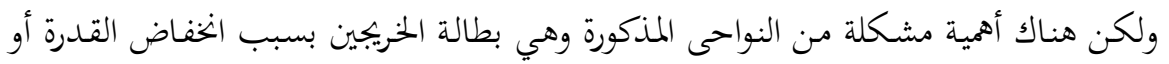

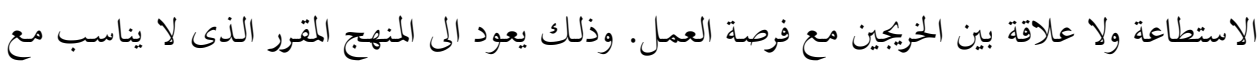

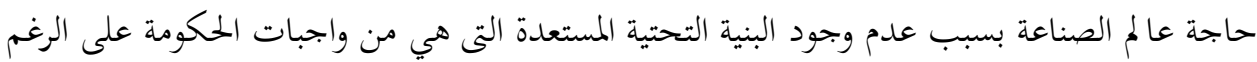

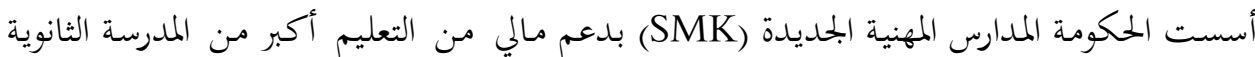

(SMA)

لذلك لا بد أن تحقق التوازن بين احتياجات التعليم والمهارات الأكاديمية لدخول سوق العمل .

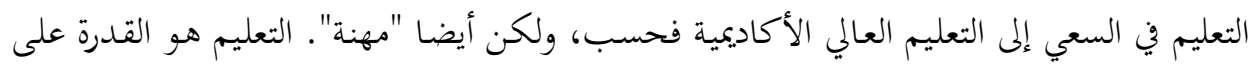

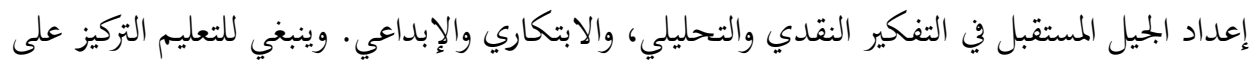

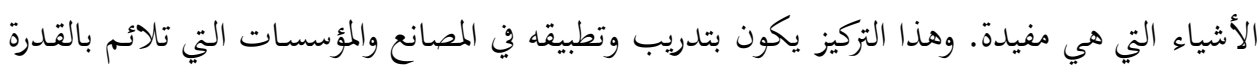

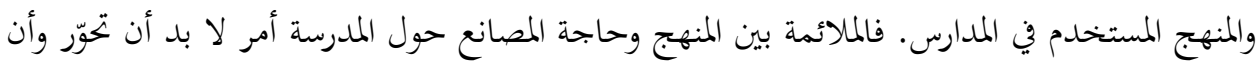

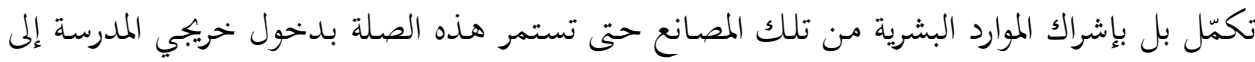

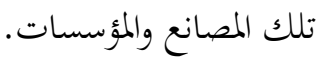

\section{روح الاعتماد وروح المبادرة لدى المتعلمين لفتح فرصة العمل}

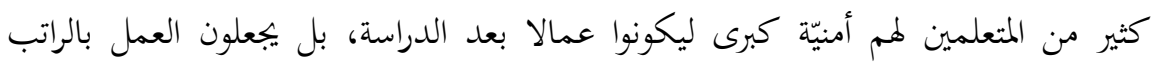

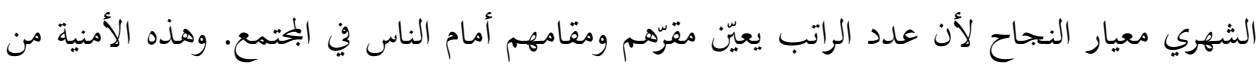

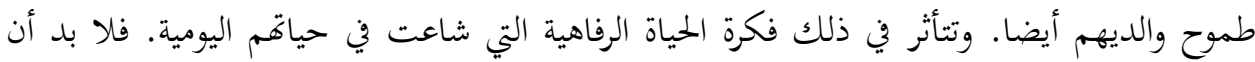
نغير هذه الفكرة بفكرة حسنة وواعية ووسيلة التغيير هي التربية.

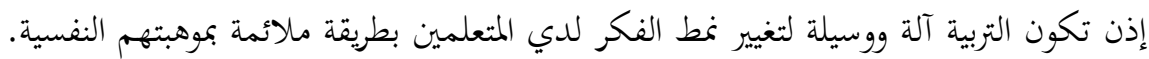

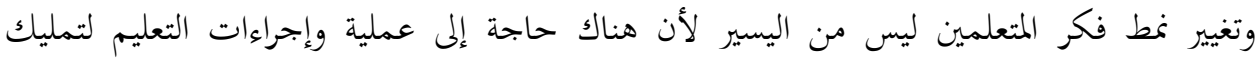

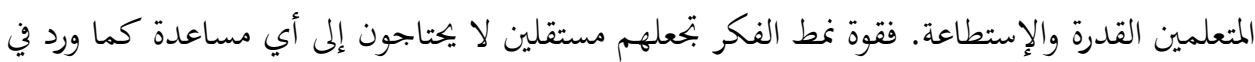

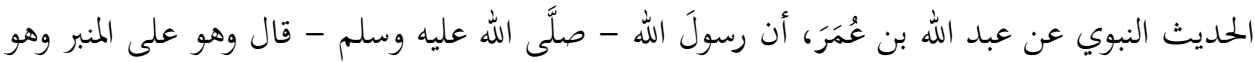


يَذكر الصَََّقَة والتعففَ منها، والمسألة: "اليدُ العُليا خيرٌٌ مِن اليد السُّفلى، واليدُ العُليا المنفقَة، والسُّفلى

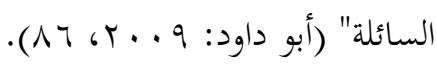
دل الحديث على أن المعطي هو المستطيع الذي له قدرة لإعطاء الشيئ وذلك لأنه هو المستقلّ المّل

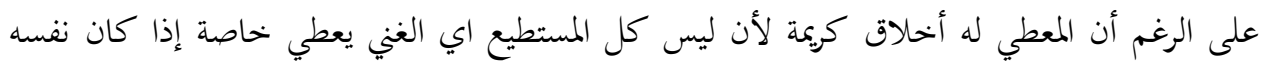

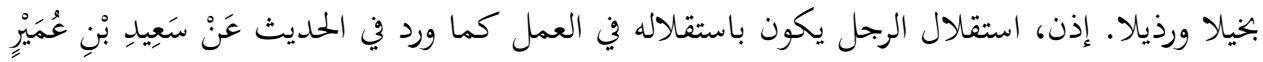

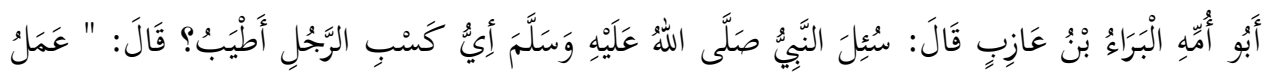

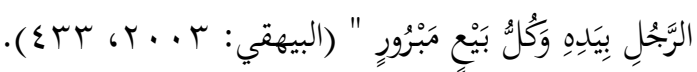

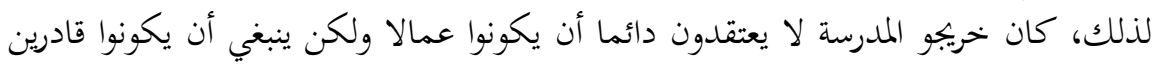

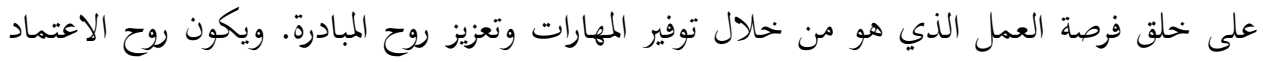

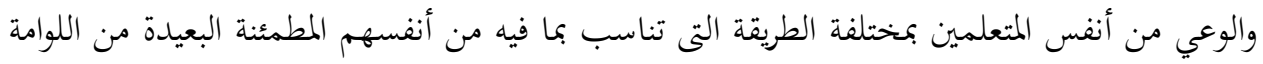

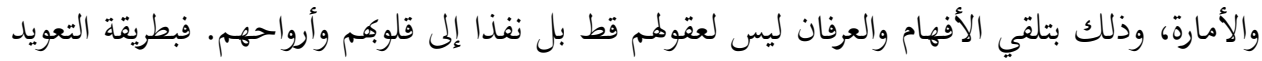

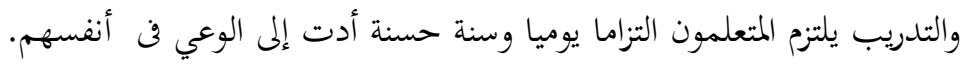

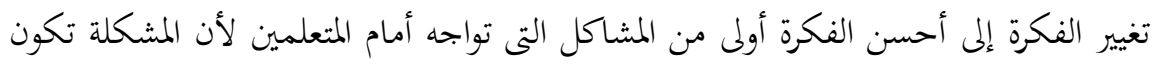

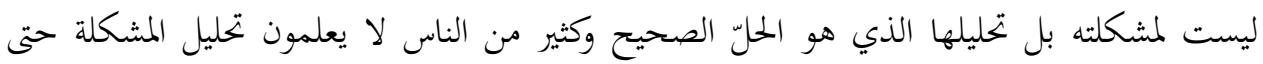

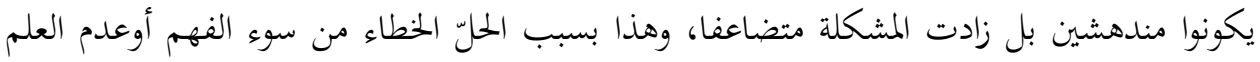

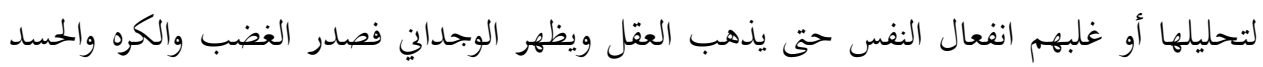
واللمزة والهمزة وغيرها من سوء الأخلاق.

مما يؤثر في دافعية الطلبة للتعلم والتحفيز عليه هناك نوعادهان من التهان العوامل وهي: أولا، العوامل

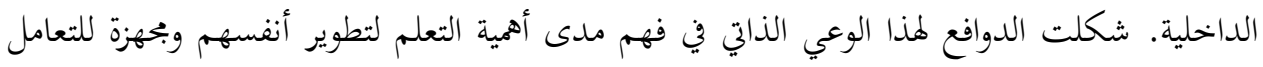

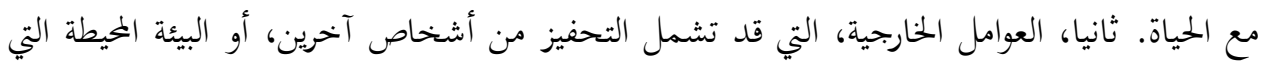

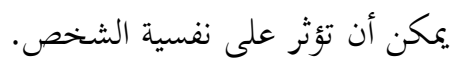

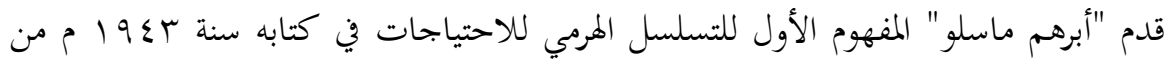

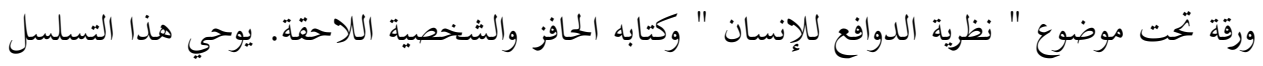

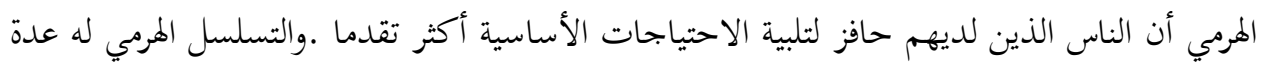

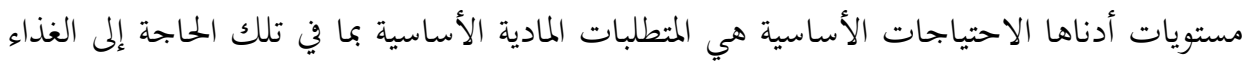

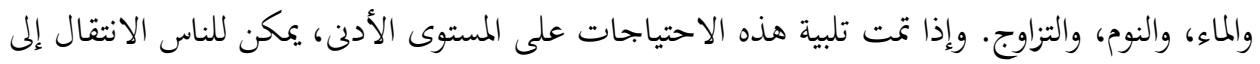




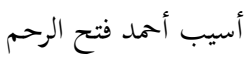

المستوى التالي من الاحتياجات، والتي هي للسلامة والأمن. ويكون ذلك الوعي بمختلف الحاجة

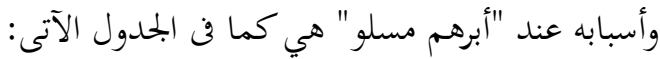

الصورة المان

هرم (ماسلو) • 199 19 تسعة مرحلة

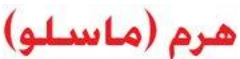

نظرية في التحفيز الإنساني

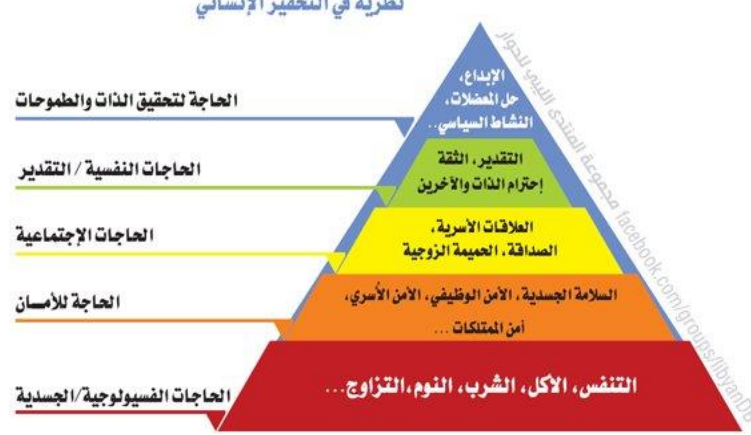

• • اختلافات الفسيولوجية (الحاجات الفسيولوجية)، مثل الجوع، والعطش، والرغبة الجنسية. • اختلافات الشعور بالأمن (احتياجات السلامة)، على حد سواء عقليا وجسديا وفكريا.

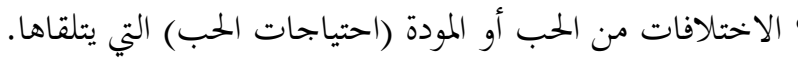

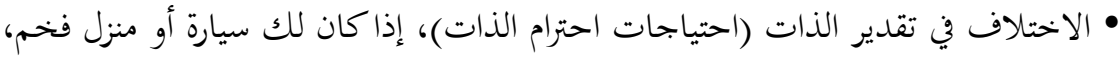
والمكاتب، وغيرها.

• الاختلافات في تحقيق الذات (الذات)، وتوافر الفرص لشخص ما لتطوير إمكأنيات أن هناك في له التي تحولت إلى القدرة الحقيقية.

وتوصلت هذه الاختلافات في هذا العهد باختلاف الاتحاهات التربوية شرقا وغربا، إسلاميا

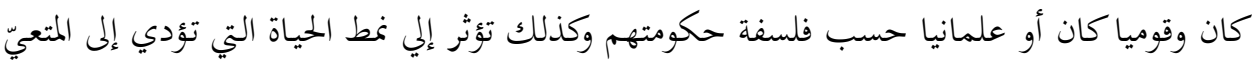
والواقعيّ. ودنّل هذا المتعي للتربية والتعليم حتي يذهب روح الجهاد لأن اتجاه التعليم صار ماديا مثل

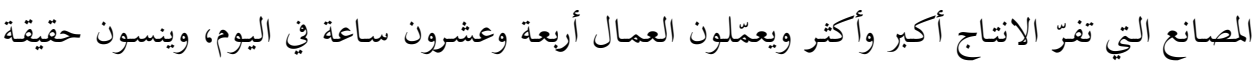
غرض الحياة وذلك تأثير الرأسمالية المخيطة في حياة الناس بل بسهم قليل يريد أن ينال ربحا كبيرا. لـذلك قال محمد منير مرسى إن الاتباهـات التربويـة في العصور الحديثة هي اقتبـاس النظام

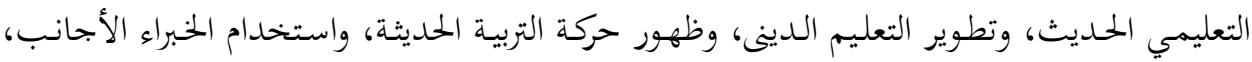

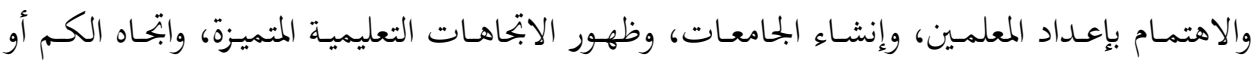


سياسة الماء والهواء (طه حسين)، واتحاه الكيف أو تعليم الصفوة (اسماعيل القبانز) (محمد منير مرسى: (179. $197 \mathrm{VV}$ تتأثر هـذه الإبحاهـات بأنواع الفكرة والثورة الصـناعية في أوربـا خاصة فن فرنسـا مثل جامعـة

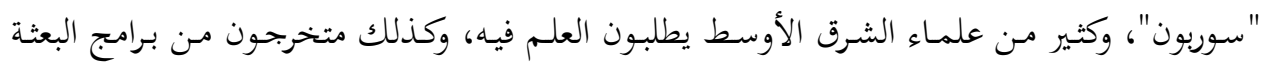

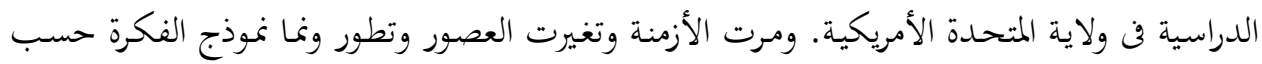
حوائجهم الواقعية ورأيهم المثالية فنظرية التربية تكون متغيرة ومتبادلة بنظرية وشكلة جديدة ولديدة.

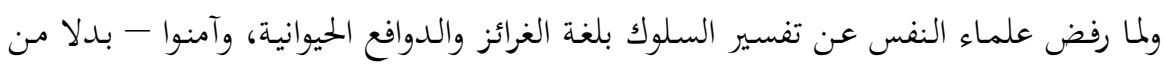

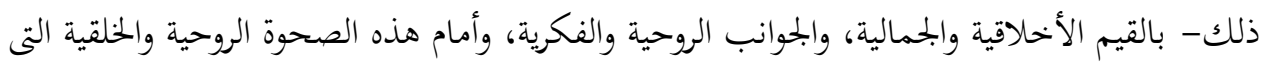

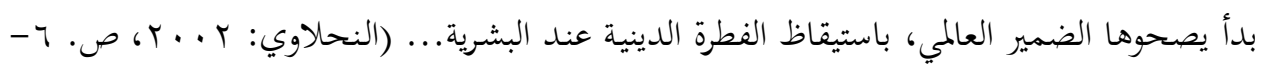

\section{النظــامي داخـل بيئسة البيـت وخارجــه}

\section{النظـامي (formal) وغيـر} (informal)،(nonformal)

إن بحاح تلك الملائمة يجب أن تدمج بحموعة واسعة من التعليم من خلال التمكين والتواصل

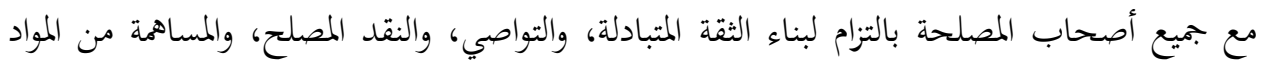

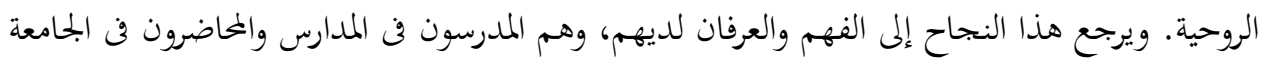
والشيوخ فن المساجد والمربون فن الشقة والوالدون فن البيوت والرؤساء فن الوزارة والمديرات فن الادادارة

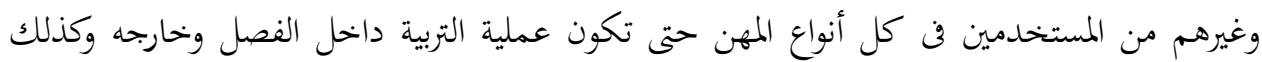

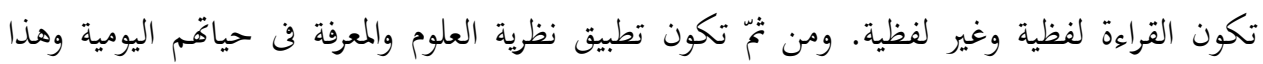
التطبيق سيسوق إلى تقدم الأمم وتفوقها.

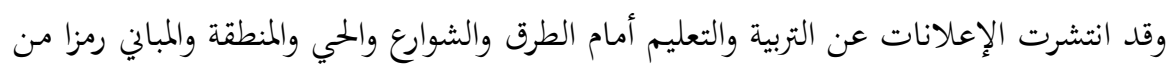

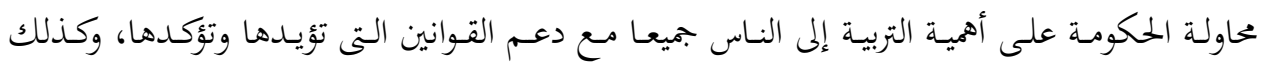

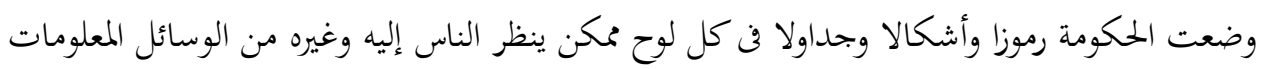

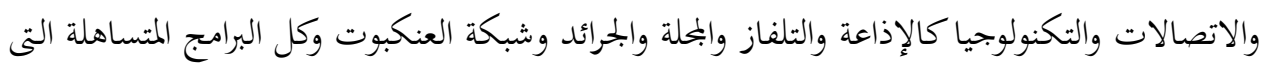
أدت إليه. - مالات 
أسيب أحمد فتح الرحم

ومراقبة النـاس والحكومة لهذه العملية تكون مداومة ومستمرة في كل العصور مع التغير إلى

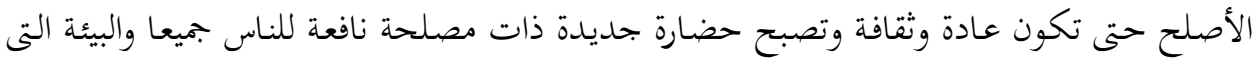

يكون الناس فيها.

كانت الأمة الإسلامية تواجه تحدياً تربويًّا من أبواب شتى، فالشباب يعانون من تخطيط ماكر

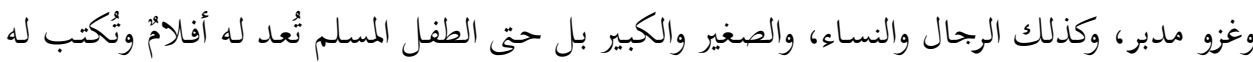

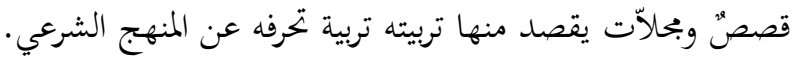

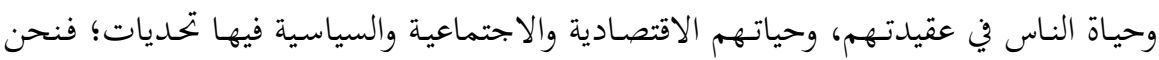

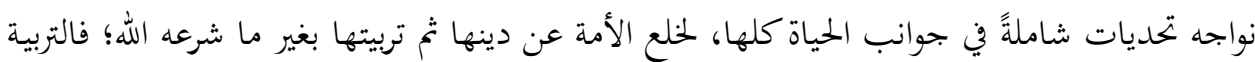

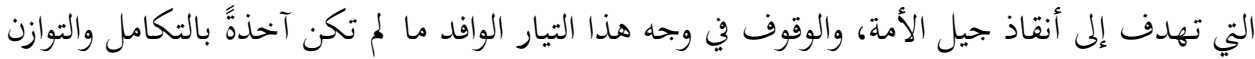

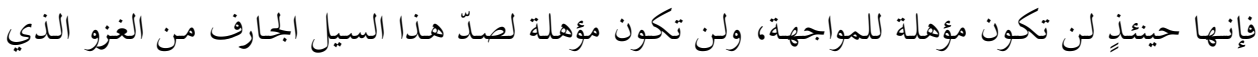

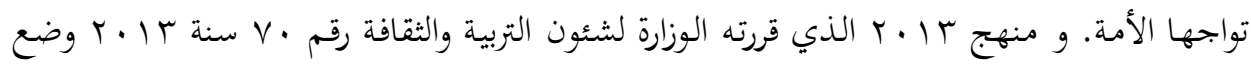

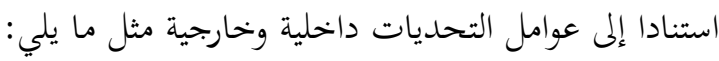

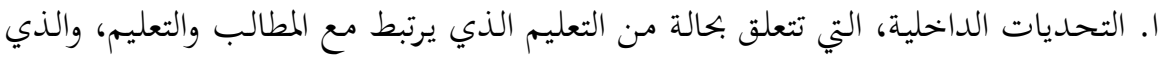

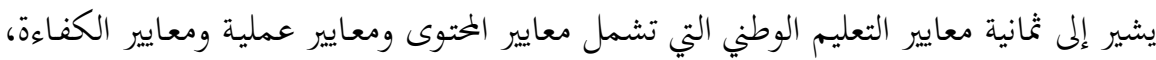
ومعايير تدريس وتعليم الموظفين والمرافق ومعايير التسهيلات الدراسية، ومعايير الإدارة ومعايير

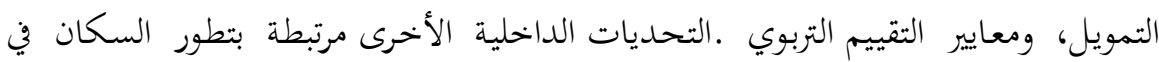

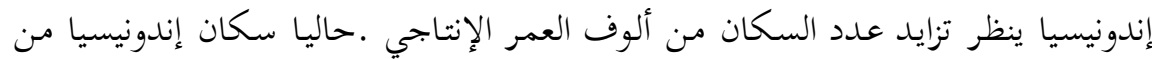

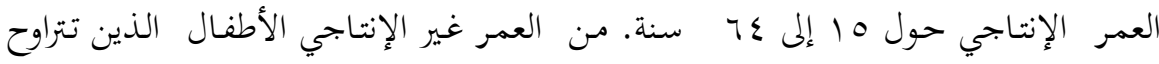

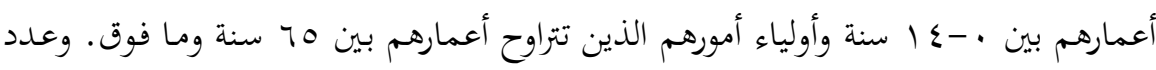

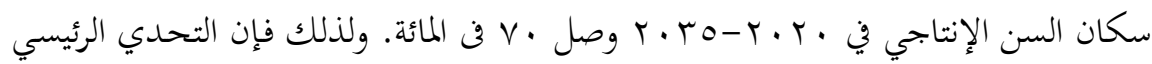

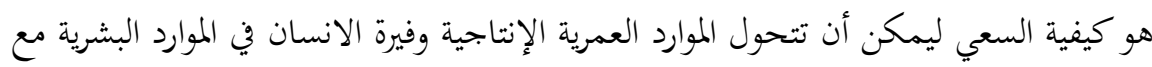
الكفاءة والمهارات من خحلال التعليم حتى لا يكون عبئا. r. ترتبط التحديات الخارجية للعولمة والقضايا المتصلة بالقضايا البيئية، وتطور التكنولوجيا لهائات والمعلومات، وصعود الصناعات الإبداعية والثقافية، وتطور التعليم على المستوى المعائية

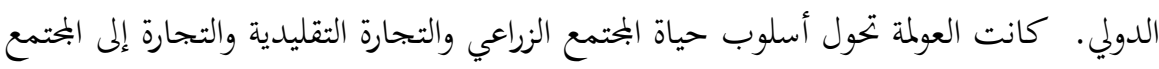

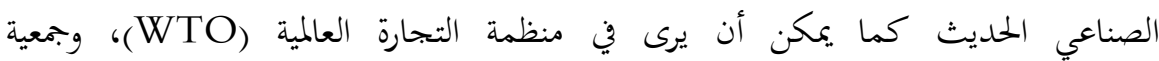


دول جنوب شرق آسيا، وبمعية التعاون الاقتصادي لآسيا والمخيط الهادئ (APEC) الاقتصادية العالمية والنفوذ والتأثير والاستثمار والتحول التعليمي .مشاركة إندونيسيا في الدراسة :

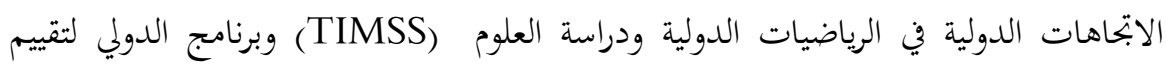

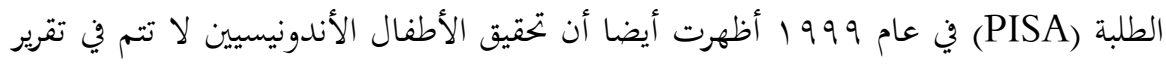

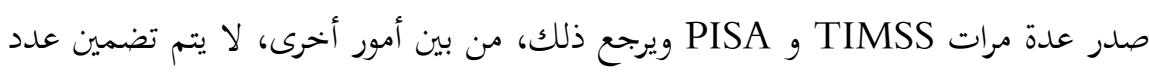
من مادة الاختبار في سؤال في PISA و TIMSS في المناهج الدراسية في أندونيسيا.

النيجة

كانت سياسة قوانين الحكومـة لاستعداد المناهج الدراسية لتكون هنـاك علاقة بين الخخريجين

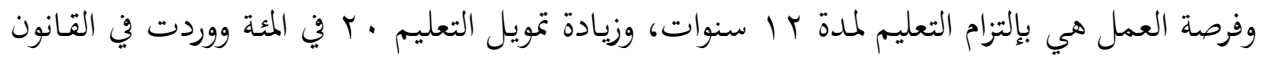

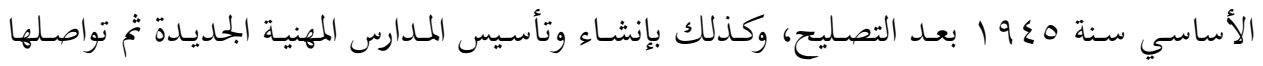

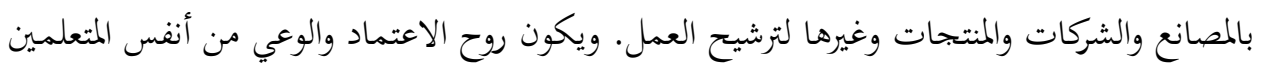

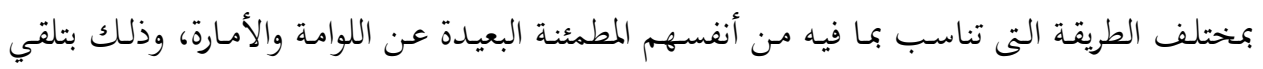

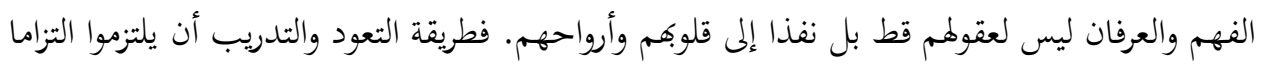

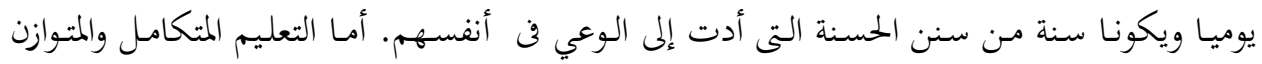

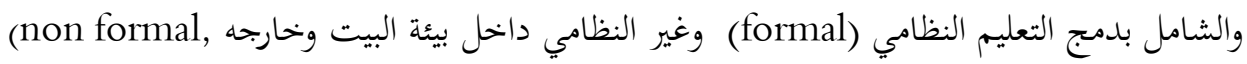
informal)

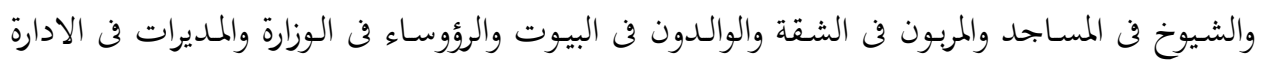

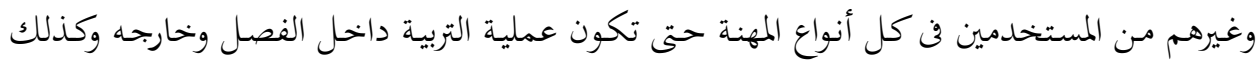

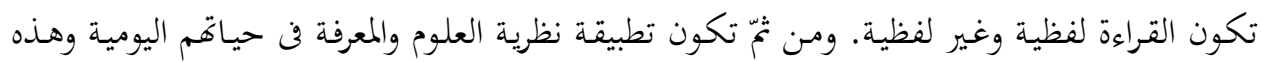
التطبيقة التي ساقت إلى تقدم الأمم وتفوقها.

المراجع أبو داود، سليمان ابن الأشعث، و ج. . . ـ سنن أبي داود، بدون المكان: دار الرسالة العالمية

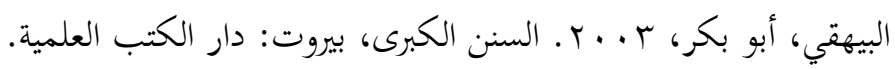

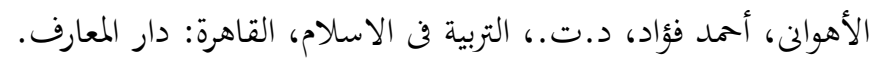




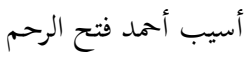

شوقى، أحمد، 1. . Y. العلم ثقافة المستقبل، القاهرة: مكتبة الأسرة.

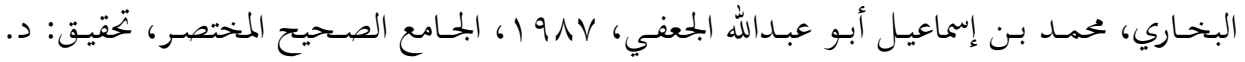
مصطفى ديب البغا. اليمامة - بيروت: دار ابن كثير.

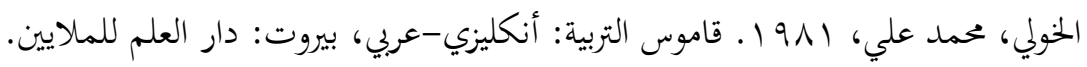
شديد، محمد، د.ت.، منهج القرآن فن التربية، ميدان سيدة زينب: بدون الناشر.

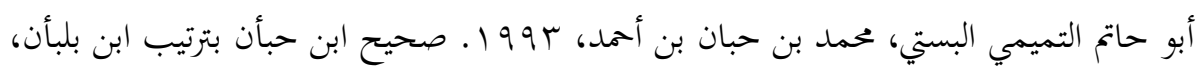

$$
\text { بيروت: مؤسسة الرسالة. }
$$

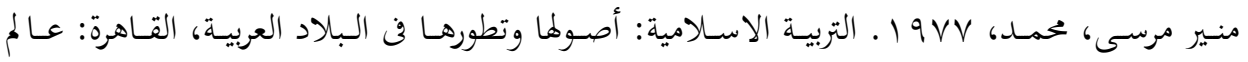
الكتب.

الشرقاوى، حسن، بر19 ا ـ نحو التربية الاسلامية، الاسكندرية: مؤسسة ثياب الجامعة.

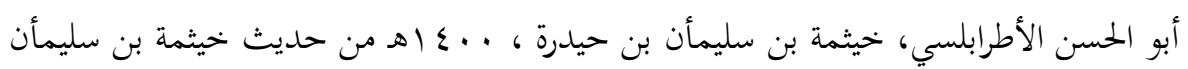

$$
\text { القرشي الأطرابلسي، بيروت: دار الكتاب العربي. }
$$

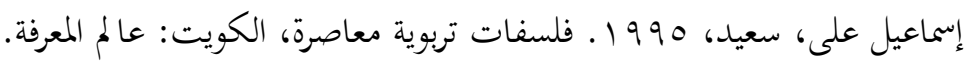
النحلاوي، عبد الرحمن، r . . r. التربية بالعبرة، دمشق: دار الفكر.

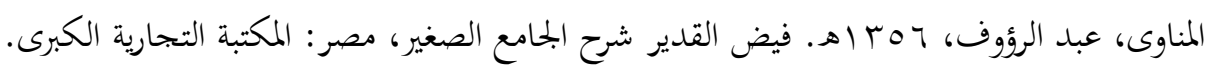
الغامدي، عبداللطيف بن هاجس، د.ت، ... 1 فكرة لتربية الأسرة. 